\title{
Multiple genetic alterations in primary cutaneous large B-cell lymphoma, leg type support a common lymphomagenesis with activated B-cell-like diffuse large B-cell lymphoma
}

\author{
Anne Pham-Ledard ${ }^{1,2}$, Martina Prochazkova-Carlotti ${ }^{1}$, Laetitia Andrique ${ }^{1}$, \\ David Cappellen ${ }^{1,3}$, Béatrice Vergier ${ }^{4}$, Fabian Martinez $^{3}$, Florent Grange ${ }^{5}$, \\ Tony Petrella ${ }^{6}$, Marie Beylot-Barry ${ }^{1,2}$ and Jean-Philippe Merlio ${ }^{1,3}$ \\ ${ }^{1}$ EA2406 Histology and Molecular Pathology of Tumors, University of Bordeaux, Bordeaux, France; \\ ${ }^{2}$ Dermatology Department, CHU Bordeaux, Bordeaux, France; ${ }^{3}$ Tumor Bank and Tumor Biology Laboratory, \\ CHU Bordeaux, Bordeaux, France; ${ }^{4}$ Pathology Department, CHU Bordeaux, Bordeaux, France; ${ }^{5}$ Dermatology \\ Department, CHU Reims, Reims, France and ${ }^{6}$ Pathology Department, CHU Dijon, Dijon, France
}

\begin{abstract}
Primary cutaneous large B-cell lymphoma, leg type has been individualized from nodal diffuse large B-cell Iymphoma. The objective of this study was to screen primary cutaneous large B-cell lymphoma, leg type for genetic alterations recently described in nodal diffuse large B-cell lymphoma. Skin biopsies from 23 patients were analyzed for IRF4, BCL2, BCL6, and MYC expression. FISH testing was performed for BCL2, BCL6, MYC with separation probes and for CDKN2A and PRDM1/BLIMP1 deletion. Multiple sequential FISH analyses with up to six probes were performed to define samples with multiple cytogenetic alterations. MYD88 mutations were studied by Sanger sequencing. All cases but one displayed at least one genetic alteration (96\%). Nine patients exhibited a single genetic mutation and 12 combined several alterations (52\%). We observed a split for $B C L 2$, $B C L 6$, or $M Y C$ in $1 / 23,6 / 23$, and $3 / 23$ of cases, respectively. No double-hit lymphoma was observed. CDKN2A deletion was detected by FISH in only $5 / 23$ cases. BLIMP1 and/or $6 q$ deletion was observed at a higher rate in $10 / 20$ of cases. No correlation between rearrangement and immunohistochemical expression was found for BCL2 or MYC. FISH tracking of sequential hybridizations showed that several alterations were carried by the same nuclei. The p.L265P MYD88 mutation was found in 11/18 (61\%) of cases. Contrary to most cutaneous lymphomas that rarely harbor primary genetic alteration of their nodal histological equivalent, primary cutaneous large B-cell lymphoma, leg type seems to be a 'cutaneous counterpart' of activated B-cell-like diffuse large B-cell lymphoma with a similar cytogenetic profile and a high rate of MYD88 oncogenic L265P mutation. This also suggests a common lymphomagenesis with NF- $\kappa \mathrm{B}$ activation, strong IRF4 expression and terminal B-cell differentiation blockage. Our data support the use of therapies targeting NF- $k B$, as most patients displayed disease progression and resistance to conventional therapies.

Modern Pathology (2014) 27, 402-411; doi:10.1038/modpathol.2013.156; published online 13 September 2013
\end{abstract}

Keywords: BCL2; BCL6; diffuse large B-cell lymphoma; MYC; MYD88; NF- $\kappa$ B; primary cutaneous large B-cell lymphoma, leg type

Primary cutaneous large B-cell lymphoma, leg type has been individualized in the WHO classification as an aggressive disease involving preferentially the

Correspondence: Professor J-P Merlio, MD, PhD, EA 2406 Histology and Molecular Pathology of Tumors, University of Bordeaux Bat. 3B, 2ème étage, Zone Nord 146 rue Léo Saignat, 33076 Bordeaux, France.

E-mail: jp.merlio@u-bordeaux2.fr

Received 22 April 2013; revised 12 July 2013; accepted 14 July 2013; published online 13 September 2013 leg(s) with rapidly growing tumor(s) in elderly and a 5-year survival around $40 \% \cdot{ }^{1-4}$ It is made of diffuse and confluent sheets of monotonous large B cells in the dermis and frequent infiltration of the subcutaneous tissue. Tumor cells are characterized by a high expression of BCL2, IRF4/MUM1 and FOXP1 proteins with an aberrant expression of the germinal-center BCL6 protein. ${ }^{5,6}$ At diagnosis, age, leg involvement, extent of skin disease, and CDKN2A (P16) inactivation have been found as predictive for progression and death..$^{3,6-8}$ 
Contrary to nodal diffuse large B-cell lymphomas, few studies have identified molecular pathways contributing to primary cutaneous large B-cell lymphoma, leg type oncogenesis and from what stage of B-cell differentiation such lymphoma arise. In nodal diffuse large B-cell lymphomas, gene expression profiling has identified two main signatures corresponding to the differentiation stage of the cell of origin: germinal center or post-germinalcenter activated B cell. ${ }^{9,10}$ Gene expression profiling has suggested that primary cutaneous large B-cell lymphoma, leg type displays the profile of activated B-cell subtype while primary cutaneous follicle center lymphoma is similar to the germinal-center category. ${ }^{11}$ Several immunohistochemical studies of nodal diffuse large B-cell lymphoma have shown that gene expression profiling categorization could be substituted by several appropriate algorithms with a hierarchical set of monoclonal antibodies (IRF4/MUM1, BCL6 and CD10). ${ }^{12,13}$ In primary cutaneous large B-cell lymphoma, leg type, the strong expression of BCL2, FOXP1, and IRF4/ MUM1 has also been suggestive of activation of the $\mathrm{NF}-\kappa \mathrm{B}$ signaling pathway in the absence of IRF4/ MUM1 rearrangement. ${ }^{3,5,14}$

Indeed, activated B-cell-like nodal diffuse large B-cell lymphoma have been recently shown to harbor several genetic mutations involving either the B-cell receptor signaling pathway $(C D 79 B)$ or $M Y D 88$, a gene encoding a signaling protein of the Toll-like receptor pathway. ${ }^{15,16}$ Mutations of TNFAIP3/A20 and CARD11 alterations also contribute to NF- $\kappa \mathrm{B}$ pathway constitutive activation transactivating IRF4 in a positive feedback oncogenic loop. ${ }^{17-19}$ Moreover, BLIMP1/PRDM1 inactivation by genetic loss or mutation was shown to disrupt post-germinal-center terminal B-cell differentiation. ${ }^{20,21}$ We recently reported that primary cutaneous large B-cell lymphoma, leg type harbor at a striking elevated level (69\%) a unique driver mutation (L265P) of MYD88 ${ }^{22}$ previously identified both at the genetic and functional level in $29 \%$ of activated B-cell-like nodal diffuse large B-cell lymphoma. ${ }^{16}$

Besides deciphering lymphomagenesis, the knowledge of oncogenic mutations can guide therapeutic strategies targeting BCR signaling and IRF4. ${ }^{19}$ So far, a combination of polychemotherapy adapted to the age of patients with rituximab appears as the better first-line therapy in primary cutaneous large B-cell lymphoma, leg type, as in nodal diffuse large B-cell lymphoma. ${ }^{23,24}$ However, skin relapses and extracutaneous spreading occur in about half of the patients, and the 5-year overall survival in only $40 \%{ }^{3,6}$ In nodal diffuse large B-cell lymphoma, the activated B-cell-like subtype is also characterized by a poorer response to anthracyclin-based chemotherapy than the germinal-center-like type. ${ }^{10,13}$ Moreover, BCL2, BCL6, MYC rearrangements, or CDKN2A (P16) deletion have been shown associated with a worse prognosis in patients with nodal diffuse large B-cell lymphoma treated with polychemotherapy plus rituximab. ${ }^{25-31}$ The presence of such chromosomal rearrangements has also been reported in cutaneous B-cell lymphoma series including only very few cases of primary cutaneous large B-cell lymphoma, leg type. ${ }^{32,33}$ This prompted us to investigate the status of BCL2, MYC, BCL6, $C D K N 2 A$, and BLIMP1 loci using FISH in our homogeneous series and to determine their prognosis impact. In cases harboring multiple gene loci alterations, we set up an original sequential hybridization procedure to determine if tumor cells combine several cytogenetic abnormalities and to look for clonal heterogeneity.

\section{Materials and methods}

\section{Patient Selection}

Cases were retrieved retrospectively from the University Hospital of Bordeaux, France $(n=15)$ and from the French study group of cutaneous lymphomas $(n=8)$, from 1992 to 2012 . The study was performed after patient information and registration of absence of opposition according to the guidelines of the French Bioethical law for noninterventional research studies and to the Declaration of Helsinki principles. The diagnosis was confirmed by review of cases by pathologists and physicians of the French Group of Cutaneous Lymphoma, according to the WHO-EORTC classification. ${ }^{2,4}$ Patients with formalin-fixed paraffin-embedded skin tissue available for FISH study and giving informative FISH results were included $(n=23)$. Out of these 23 patients, 18 had already been included in previous studies about primary cutaneous large B-cell lymphoma, leg type by our team or by the French study group of cutaneous lymphoma. $3,14,22$

\section{Histological and Immunohistochemistry Data}

Sections (3- $\mu \mathrm{m}$ thick) of formalin-fixed paraffinembebbed skin biopsies were stained with BCL2 (clone 124, DAKO, Les Ulis, France), IRF4/MUM1 (clone mum1p, DAKO), BCL6 (clone PGB6P, DAKO), CD10 (clone 56C6, NOVOCASTRA, Leica, Nanterre, France), and c-MYC (clone Y69, EPITOMICS, Burlingame, CA). The cutoff for tumor positivity was set at $30 \%$ of tumor cells staining for each antibody, $5,12,34$ except for c-MYC (nuclear staining in $>50 \%$ of tumor cells). ${ }^{35}$ All cases were scored without knowledge of FISH results or patient outcome.

\section{Interphase FISH Analysis}

Tissue sections (4- $\mu \mathrm{m}$ thick) were prepared from formalin-fixed paraffin-embebbed skin tumoral biopsies. After dewaxing and rehydratation of tissue sections, samples were pretreated by incubating samples $10 \mathrm{~min}$ in a pre-treatment (Histology FISH 
accessory kit DAKO) prewarmed at $95^{\circ} \mathrm{C}$, then were left to cool at ambient temperature during $15 \mathrm{~min}$, and washed 3 min with distilled water. Then, slides were incubated $15 \mathrm{~min}$ with protease solution (VYSIS, ABBOTT molecular, Rungis, France) at $37^{\circ} \mathrm{C}$, then washed two times with distilled water. Thereafter, samples were dehydrated by ethanol series and dried at ambient temperature. Hybridizations were conducted with labeled probes for BCL2, $M Y C, B C L 6$ (FISH DNA split signal, DAKO), and CDKN2A (LSI p16 (9p21)/CEP9 Dual Color Probe, Vysis, ABBOTT Molecular) to study the occurrence of alterations affecting these loci. Cases showing a breakpoint at the $M Y C$ locus were also investigated with the LSI IGH-MYC-CEP8 tricolor FISH-probe kit (Vysis, ABBOTT Molecular).

We also investigate the presence of a BLIMP1 locus deletion by FISH using the following BAC probes: the $6 \mathrm{q} 21$ probe for the BLIMP1 locus RP101M23 was labeled with SpectrumRed, the 6q25 RP-11-589G2 labeled with SpectrumGold as control probe on 6q, and the 6p25 CTD-2308G5 labeled with SpectrumGreen as control probe on $6 \mathrm{p}$.

After post-hybridization washing, slides were counterstained with 4',6-diamidino 2-phenylindole. For BCL2, BCL6, and MYC analysis, cells harboring a gene breakpoint, one yellow fusion $(\mathrm{F})$ signal in addition to one red and one green signals (split) were observed while the FISH pattern was $2 \mathrm{~F}$ signal in normal nuclei. Minor breakpoints in the BCL2 or $M Y C$ gene locus could also provide other patterns with Red or Green extra-signals (2F-2G-1R or 2F-1G$2 \mathrm{R}$ ), as well as complex patterns with one or more rearranged allele in a polyploid sample. Copy number variation were also taken into account, such as extracopy (more than $2 \mathrm{~F}$ pattern), and deletion (less than $2 \mathrm{~F}$ pattern). For $C D K N 2 A$ and $B L I M P 1$, the ratio between locus-specific and centromere for CDKN2A or control probes for BLIMP1 signals was recorded in individual cells. For BLIMP1, 'interstitial deletion' was recorded when only the BLIMP1 locus signal was lacking, and ' $6 \mathrm{q}$ deletion' when both BLIMP1 locus and 6q25 signals were lacking. At least 10 high-power fields ( $\times 63$ objective) of tumor areas were analyzed and scoring was determined independently on 100 non-overlapped nuclei by two observers (AP-L and MP-C). Positivity was determined above a 5\% threshold for split signal or separation probes and 15\% threshold for deletion, gain, or amplification.

\section{Sequential hybridization on the Same Slide with Different Probes}

To show multiple chromosomal alterations in the same tumor, we developed an original FISH strategy with sequential hybridizations. After the first FISH analysis, the coverslip was removed and the slide washed during $5 \mathrm{~min}$ in phosphate buffer saline. After dehydration in alcohol series, the slide was dried at ambient temperature and denatured during
5 min in formamide $70 \% / 2 \times$ SCC warmed at $70{ }^{\circ} \mathrm{C}$, and again dehydrated. The further probes were denatured in a hot water bath. This procedure of sequential hybridizations could be generally conducted at least six times on the same slide, or stopped in case of deterioration of nucleus morphology at 4',6-diamidino 2-phenylindole staining. Controls between sequential steps showed the absence of remaining signals of the previous hybridization.

\section{Relocalization of Nucleus in Samples Harboring Multiple Gene Alterations}

Sequential hybridizations were analyzed with a fluorescence microscope (Imager Z2, ZEISS) and software (Metasystems, Altlussheim, Germany) permitting to relocalize a tumor area on a same slide by the use of a motorized microscope stage (Marzhauser, Wetzlar, Germany). Moreover for each genetic alteration, the percentage of cells with an aberrant profile was recorded and compared with other genes data.

\section{MYD88 Analysis}

MYD88 analysis was performed on matched tumoral and constitutional DNA as described before. ${ }^{22}$

\section{Statistical Analysis}

Disease-specific survival was calculated from the date of diagnosis to the date of disease-related death or last follow-up without event. Overall survival was determined from the date of diagnosis to the date of death of any cause. Disease-free survival was calculated as the time relapsed from diagnosis date to the date of recurrence or death. Potential prognosis factors examined were patient's age (dichotomized in two classes: $>75$ years $v s<75$ years) and gender, extent of cutaneous involvement according to TNM classification, site of cutaneous lesions (leg versus non-leg localization), presence of an ulceration, first-line therapy (polychemotherapy with rituximab versus other therapy), and presence of a FISH abnormality or MYD88 mutation. Survival curves were plotted using the Kaplan-Meier method and compared using the log-rank test for each prognosis factor (univariate analysis). Statistical analysis was performed using MedCalc software, version 12.4.0 (http://www.medcalc.org).

\section{Results}

The main clinical characteristics of patients at diagnosis, follow-up, immunohistochemical, and FISH results are summarized in Tables 1 and 2 .

\section{Clinical Data at Diagnosis}

Twenty-three patients with primary cutaneous large B-cell lymphoma, leg type consisted of 13 women 
Table 1 Clinical characteristics and follow-up of patients with primary cutaneous large B-cell lymphoma, leg type included in the study

\begin{tabular}{|c|c|c|c|c|c|c|c|c|c|}
\hline $\begin{array}{l}\text { No. of } \\
\text { case }\end{array}$ & $\begin{array}{l}\text { Gender/ } \\
\text { age }\end{array}$ & Site & Ulceration & $T N M$ & Therapy & $C R$ & $\begin{array}{l}\text { Skin relapse } \\
\text { (months) }\end{array}$ & $\begin{array}{c}\text { Extracutaneous } \\
\text { progression } \\
\text { (months, site) }\end{array}$ & $\begin{array}{l}\text { Final status } \\
\text { (months of } \\
\text { follow-up) }\end{array}$ \\
\hline 1 & $\mathrm{M} / 59$ & Leg & No & T2N0M0 & RT & No & - & Yes (8, cerebral) & DD (13) \\
\hline 2 & $\mathrm{M} / 72$ & Arm & No & T2NoMo & RT & Yes & Yes (10) & Yes (24, digestive) & $\mathrm{DD}(26)$ \\
\hline 3 & $\mathrm{~F} / 88$ & Arm & Yes & T2NoMo & PC & No & - & No & $\mathrm{DD}(5)$ \\
\hline 4 & $F / 88$ & Leg & No & T2aNoM0 & $\mathrm{R}-\mathrm{PC}+\mathrm{RT}$ & Yes & Yes (32) & No & DD (46) \\
\hline 5 & $\mathrm{~F} / 83$ & Trunk & No & T2cNoMo & R-PC & Yes & No & No & CR (17) \\
\hline 6 & $\mathrm{M} / 62$ & Leg & No & T2bNoM0 & R-PC & Yes & No & No & CR (52) \\
\hline 7 & $\mathrm{M} / 64$ & Leg & NA & T2xN0M0 & Surgery & No & - & Yes $(6$, liver $)$ & DD (8) \\
\hline 8 & $\mathrm{~F} / 83$ & Leg & No & T1aNoMo & Surgery & Yes & Yes(38) & No & DA (41) \\
\hline 9 & $\mathrm{~F} / 83$ & All/Leg & NA & T3bNoM0 & RT & No & - & Yes (2, bone) & $\mathrm{DD}(5)$ \\
\hline 10 & $F / 88$ & Leg & No & T1aN0M0 & $\mathrm{PC}+\mathrm{RT}$ & Yes & Yes(34) & Yes (37, cerebral) & DD (39) \\
\hline 11 & $\mathrm{M} / 81$ & Head & NA & T1xN0M0 & RT & Yes & Yes (4) & No & DD (45) \\
\hline 12 & $\mathrm{~F} / 71$ & Leg & NA & T1xN0M0 & $\mathrm{PC}+\mathrm{RT}$ & Yes & Yes (1) & Yes (22, breast) & DD (37) \\
\hline 13 & $\mathrm{~F} / 77$ & Leg & NA & T2aNoM0 & $\mathrm{PC}+\mathrm{RT}$ & Yes & Yes (15) & No & DD (172) \\
\hline 14 & $\mathrm{~F} / 86$ & Leg & NA & T2xNoM0 & RT & Yes & Yes (4) & No & CR (104) \\
\hline 15 & $F / 63$ & Leg & No & T2bNoM0 & R-PC & Yes & No & No & CR (28) \\
\hline 16 & $\mathrm{M} / 67$ & Head & Yes & T2xN0M0 & PC & Yes & NA & NA & CR (2) \\
\hline 17 & $\mathrm{~F} / 71$ & Leg & NA & T1xNoM0 & PC & Yes & Yes(22) & Yes $(55$, cerebral) & $\mathrm{DD}(61)$ \\
\hline 18 & $\mathrm{~F} / 81$ & Trunk & No & T3aN0M1 & R-PC & Yes & Yes (9) & Yes ( 0 , bone) & DD (16) \\
\hline 19 & $\mathrm{~F} / 75$ & Leg & No & T1xN1M0 & R-PC & Yes & Yes (8) & Yes ( 0 , node) & $\mathrm{DD}(68)$ \\
\hline 20 & $\mathrm{~F} / 83$ & Leg & Yes & T2bN1M0 & R-PC & No & - & Yes ( 0 , node) & $\mathrm{DD}(11)$ \\
\hline 21 & $\mathrm{M} / 75$ & Arm & No & T1bN1M0 & R-PC & Yes & Yes (14) & Yes(0, node) & DD(18) \\
\hline 22 & $\mathrm{M} / 90$ & Leg & Yes & T2bN0M0 & R-PC & Yes & Yes (10) & & AWD (14) \\
\hline 23 & $\mathrm{M} / 78$ & All/Leg & Yes & T3bNoM0 & R-PC & No & - & No & $\mathrm{DD}(2)$ \\
\hline
\end{tabular}

AWD: alive with disease; CR: complete remission; DA: death another cause; DD: death of disease; NA: not available; PC: polychemotherapy; R-PC: Rituximab + polychemotherapy; RT: radiotherapy.

and 10 men, with a median age of 78 years (range, 59-90 years; Table 1). Seven patients had a solitary lesion classed $\mathrm{T} 1,13$ were $\mathrm{T} 2$ (regional skin involvement) and 3 had generalized skin involvement (T3). Four patients had extracutaneous involvement at initial staging but were primarily referred to our dermatological department for primary cutaneous presentation and initial biopsy specimens with a diagnosis of large B-cell lymphoma, leg type: 3 had limb tumor and regional draining lymph node spreading (cases 19-20-21), one had a skin tumor of the trunk with contiguous costal involvement (case 18). The most frequently involved localization was the leg (16 out of $23,70 \%$ ), associated with generalized skin involvement in two cases (9\%), 2 patients had head and neck lesion (9\%), 3 patients had arm involvement (13\%), and 2 patients had lesion on the trunk (4\%). Six patients had an ulcerated skin lesion out of 18 with such available information.

\section{First-Line Therapy, Follow-Up, Relapse Rate}

Combination of systemic polychemotherapy with rituximab was the most common first-line treatment ( $n=10,43 \%$; Table 1). Six patients received systemic chemotherapy alone $(26 \%)$, followed by adjuvant radiotherapy in three cases. Five patients were exclusively treated by radiotherapy $(22 \%)$, and two patients had only surgery $(9 \%)$. The mean and median follow-up was 36 and 26 months, respec- tively (range 2-172 months). Seventeen patients $(74 \%)$ were followed until death. Complete remission was obtained for 17 patients $(74 \%)$. Patients without complete response $(n=6)$ had disease progression (at the skin level only in one case or extracutaneous in five cases), whichever first-line therapy. Among the 17 patients with complete response, $13(76 \%)$ experienced at least one cutaneous relapse. The mean and median delay for cutaneous relapse was 15 and 14 months after complete remission, respectively (range 1-38 months). Eleven patients developed extracutaneous disease during follow-up (47\%), with cerebral $(n=3)$, node $(n=2)$, bone $(n=2)$, breast $(n=1)$, digestive $(n=1)$, pericardia $(n=1)$, and liver $(n=1)$ involvement. The mean and median delay for the development of extracutaneous progression was 14 and 6 months after diagnosis, respectively (range 0-55 months). At the final point, 5 patients were alive in complete remission, one patient was alive with disease, and 16 patients died of lymphoma (median delay of 39 months), whereas one died of another disease.

\section{Immunohistochemical and Genetic Data}

We observed an abnormal genetic profile for at least one gene studied among BCL2, BCL6, MYC, CDKN2A, BLIMP1 or MYD88 in 22 out of 23 patients (96\%) (Table 2, Figures 1 and 2). The most frequent 
Table 2 Immunohistochemistry and genetic results of patients with primary cutaneous large B-cell lymphoma, leg type included in the study

\begin{tabular}{|c|c|c|c|c|c|c|c|}
\hline$N^{\circ}$ & $\begin{array}{l}\text { IHC MUM1/BCL2 } \\
\text { BCL6/CD10/MYC }\end{array}$ & FISH BCL2 & FISH BCL6 & FISH MYC & FISH CDKN2A & FISH BLIMP1 & MYD88 \\
\hline 1 & $-1+1-1-1-$ & $\mathrm{N}$ & $\mathrm{N}$ & Split (15\%) & $\operatorname{Del}(15 \%)$ & $\mathrm{NI}$ & L265P \\
\hline 2 & $+/+/+/-/ \mathrm{ND}$ & $\mathrm{N}$ & extra & $\mathrm{N}$ & $\mathrm{N}$ & NI & L265P \\
\hline 3 & $-/+/-/-/ \mathrm{IN}$ & $\mathrm{N}$ & $\mathrm{N}$ & $\mathrm{N}$ & $\mathrm{N}$ & NI & L265P \\
\hline 4 & $+1+1+1-1+$ & Extra $(70 \%)$ & Extra $(68 \%)$ & $\mathrm{N}$ & $\mathrm{N}$ & Del 6q (78\%) & L265P \\
\hline 5 & $+1+1-1-/ \mathrm{ND}$ & $\mathrm{N}$ & $\mathrm{N}$ & $\mathrm{N}$ & $\mathrm{N}$ & Del 6q & L265P \\
\hline 6 & $+1+1+1-1-$ & $\mathrm{N}$ & Split (75\%) & $\mathrm{N}$ & $\operatorname{Del}(75 \%)$ & $\mathrm{N}$ & $\mathrm{N}$ \\
\hline 7 & $+/+I+/ \mathrm{ND} /+$ & $\mathrm{N}$ & $\mathrm{N}$ & $\mathrm{N}$ & $\mathrm{N}$ & $\mathrm{N}$ & NI \\
\hline 8 & $+1+1+1-I+$ & Extra $(80 \%)$ & Split + extra (85\%) & $\mathrm{N}$ & Extra $(80 \%)$ & Del 6q (85\%) & $\mathrm{N}$ \\
\hline 9 & $-/+/+/ \mathrm{ND} /+$ & $\mathrm{N}$ & $\mathrm{N}$ & Del & $\mathrm{N}$ & Del & IN \\
\hline 10 & $+I+I+I-/ \mathrm{IN}$ & $\mathrm{N}$ & $\mathrm{N}$ & $\mathrm{N}$ & $\mathrm{N}$ & NI & L265P \\
\hline 11 & $+1+1+1-1+$ & $\mathrm{N}$ & Split + del $(80 \%)$ & $\mathrm{N}$ & $\mathrm{N}$ & $\mathrm{N}$ & $\mathrm{N}$ \\
\hline 12 & $+/+/ \mathrm{ND} / \mathrm{ND} / \mathrm{ND}$ & $\mathrm{N}$ & $\mathrm{N}$ & Split (90\%) & Del (90\%) & NA & NA \\
\hline 13 & $+/+/ \mathrm{ND} / \mathrm{ND}$ & $\mathrm{N}$ & $\mathrm{N}$ & $\mathrm{N}$ & $\mathrm{N}$ & $\operatorname{Del}(10 \%)$ & $\mathrm{N}$ \\
\hline 14 & $+/+/ \mathrm{ND} / \mathrm{ND} /+$ & $\mathrm{N}$ & Extra $(75 \%)$ & Split (80\%) & $\mathrm{N}$ & $\mathrm{N}$ & NI \\
\hline 15 & $+1+1+1-1-$ & $\mathrm{N}$ & $\mathrm{N}$ & $\mathrm{N}$ & $\mathrm{N}$ & $\mathrm{N}$ & L265P \\
\hline 16 & $+/+1+/ \mathrm{ND} /+$ & Split (75\%) & $\mathrm{N}$ & $\mathrm{N}$ & Del (95\%) & $\mathrm{N}$ & NI \\
\hline 17 & $+/+/ \mathrm{ND} / \mathrm{ND} /+$ & Extra $(75 \%)$ & Extra $(72 \%)$ & $\mathrm{N}$ & $\operatorname{Del}(60 \%)$ & Del 6q + extra $(70 \%)$ & L265P \\
\hline 18 & $+I+I+I+I+$ & $\mathrm{N}$ & Split $(20 \%)$ & $\mathrm{N}$ & $\mathrm{N}$ & $\operatorname{Del}(20 \%)$ & L265P \\
\hline 19 & $+1+1+1-1+$ & $\mathrm{N}$ & $\mathrm{N}$ & $\mathrm{N}$ & $\mathrm{N}$ & Del (85\%) & L265P \\
\hline 20 & $+1+1+1-1-$ & $\mathrm{N}$ & Split (47\%) & $\mathrm{N}$ & $\mathrm{N}$ & $\mathrm{N}$ & $\mathrm{N}$ \\
\hline 21 & $+1+1+1-1-$ & $\mathrm{N}$ & $\mathrm{N}$ & $\mathrm{N}$ & $\mathrm{N}$ & $\operatorname{Del}(77 \%)$ & $\mathrm{N}$ \\
\hline 22 & $+/+I+I-/ \mathrm{ND}$ & $\mathrm{N}$ & Split (90\%) & $\mathrm{N}$ & $\mathrm{N}$ & Del 6q (65\%) & $\mathrm{N}$ \\
\hline 23 & $+1+1-1+1+$ & $\mathrm{N}$ & $\mathrm{N}$ & $\mathrm{N}$ & $\mathrm{N}$ & Del (80\%) & L265P \\
\hline
\end{tabular}

Del: deletion of the locus; Extra: extracopy of the locus; IHC: immunohistochemistry; N: normal; NA: not available; ND: not done; Neg: negative; NI: not interpretable.

findings were the p.L265P MYD88 mutation (c.794 $\mathrm{T}>\mathrm{C}$ ) occurring in 11 out of 18 informative cases $(61 \%)$ and the $6 \mathrm{q}$ deletions involving BLIMP1 in 11 out of 18 informative cases $(61 \%$; interstitial deletion in five cases, $6 \mathrm{q}$ deletion including BLIMP in six cases). CDKN2A (P16) deletion was observed in 5/23 cases $(22 \%)$, either homozygous $(n=2)$ or heterozygous $(n=3)$. The presence of a BCL6 breakpoint was also found in 6 out of 23 cases (26\%) and the presence of normal BCL6 locus extracopy in 5 out of 23 cases $(22 \%)$. In 3 out of $23(13 \%)$ cases, a $M Y C$ breakpoint was detected. These cases were further investigated for the IGH-MYC fusion, and fusion pattern suggestive for the $t(8 ; 14)(q 24 ; q 32)$ was observed in $2 / 3$ cases. In one case only $(1 / 23,4 \%)$, a BCL2 breakpoint was detected. There was no double- or triple-hit lymphoma for BCL6, MYC or $B C L 2$ breakpoints. Conversely, CDKN2A deletion was found associated together with either a $M Y C$ rearrangement (cases 1 and 12) or a BCL6 rearrangement (case 6) or BCL2 rearrangement (case 16) in the same patient. Extra copies of a genetic locus were frequently observed, $5 / 23(22 \%)$ for $B C L 2,5 / 23$ $(22 \%)$ for BCL6, and $1 / 23(4 \%)$ for CDKN2A. Three patients displayed extra copies of more than two loci suggesting a global polyploidy (case 4, 8, and 17). Interestingly, BCL6 expression observed in 15/ 19 cases $(79 \%)$ was found correlated with the presence of a $B C L 6$ breakpoint. Indeed, 6 cases with a BCL 6 breakpoint and 2 cases with BCL6 extracopy showed BCL6 expression, out of 15 positive cases.
Alternatively, the four cases without BCL6 expression displayed a normal BCL6 FISH pattern. Such correlation was not found for the strong BCL2 expression in all cases, with only one case with breakpoint (Table 2). No correlation was also found for MYC expression observed in 10/18 cases (55\%), with only 2 of them exhibited a MYC breakpoint.

\section{FISH Analysis: Multiple Hybridizations and Tracking of Nuclei on the Same Slide}

In cases harboring several FISH abnormalities, we observed similar percentages of abnormal nuclei in the same tumor (Table 2). Such data strongly suggest that the same tumor nuclei harbored several genetic abnormalities. Sequential hybridization of different probes and tracking of multiple pathologic areas on the same slides were conducted in cases $1,6,8$, and 12. In these samples, we observed that the same nuclei exhibited multiple gene abnormalities, as $B C L 6$ breakpoint and 6q deletion in case 8 (Figure 1a and b), $M Y C$ breakpoint and $C D K N 2 A$ heterozygous deletion in case 12 (Figure 1c and d), BCL6 breakpoint and CDKN2A homozygous deletion in case 6 (Figure 1e and f).

\section{Statistical Analysis}

Univariate analysis of disease-specific survival and overall survival showed that the presence of a 

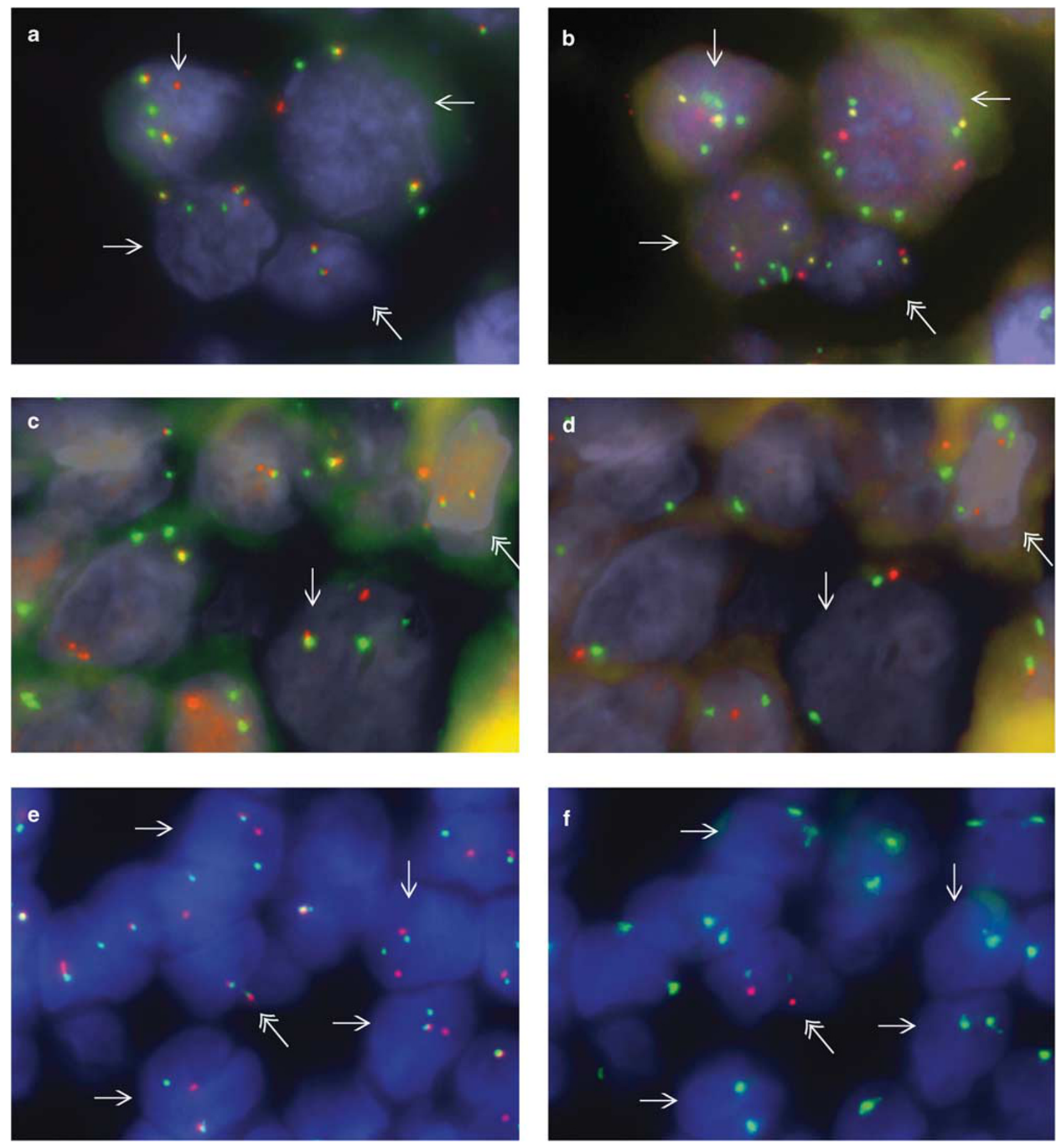

Figure 1 Sequential FISH with tracking of tumoral cells on skin sections shows that the same nuclei display several chromosomal abnormalities. (a, b) Tracking of FISH abnormalities of case 8 after sequential BCL6 split probe hybridization (a) and after BLIMP1 probe (6p Green-BLIMP1 Red-6q Gold) hybridization (b). The abnormal nuclei (arrow) carry both a BCL6 breakpoint (2Fusion (F)-1R-2Gr pattern on a) together with a BLIMP1 deletion with polysomy (6Gr-2R-2Go on b). A normal nucleus (double arrow) shows a normal $2 \mathrm{~F}$ pattern with BCL6 probe (a) and a normal 2Gr-2R-2Go pattern with BLIMP1 probe (b). (c, d) Tracking of FISH abnormalities of case 12 after sequential MYC split probe hybridization (c) and CDKN2A probe hybridization (d). (c) An abnormal nucleus (arrow) carries a MYC breakpoint (1F-2Gr-1R pattern). (d) The same nucleus (arrow) displays a CDKN2A heterozygous deletion (2Gr-1R pattern). A normal nucleus (double arrow) harbors a $2 \mathrm{~F}$ pattern for MYC probe (c) and a 2Gr-2R pattern for CDKN2A (d). (e, f) Tracking of FISH abnormalities of case 6 after sequential BCL6 split probe hybridization (e) and after CDKN2A probe hybridization (f). The abnormal nuclei (arrows) harbor a BCL6 breakpoint (1F-1R-1Gr pattern) (e) and a homozygous CDKN2A deletion (2Gr-0R pattern) (f). A normal nucleus (double-arrow) harbors a 2 Fpattern for BCL6 probe (e) and a $2 \mathrm{Gr}-2 \mathrm{R}$ pattern for $C D K N 2 A$ probe (f).

cutaneous ulceration was related with death $(P=0.0001)$ (Figure 3). Gender, age, leg localization, $\mathrm{T}$ classification, and first-line therapy had no significant effect. FISH abnormalities (BCL2/BCL6/ $M Y C$ break, CDKN2A deletion, and BLIMP1 or $6 \mathrm{q}$ deletion) were not associated with death or relapse. 


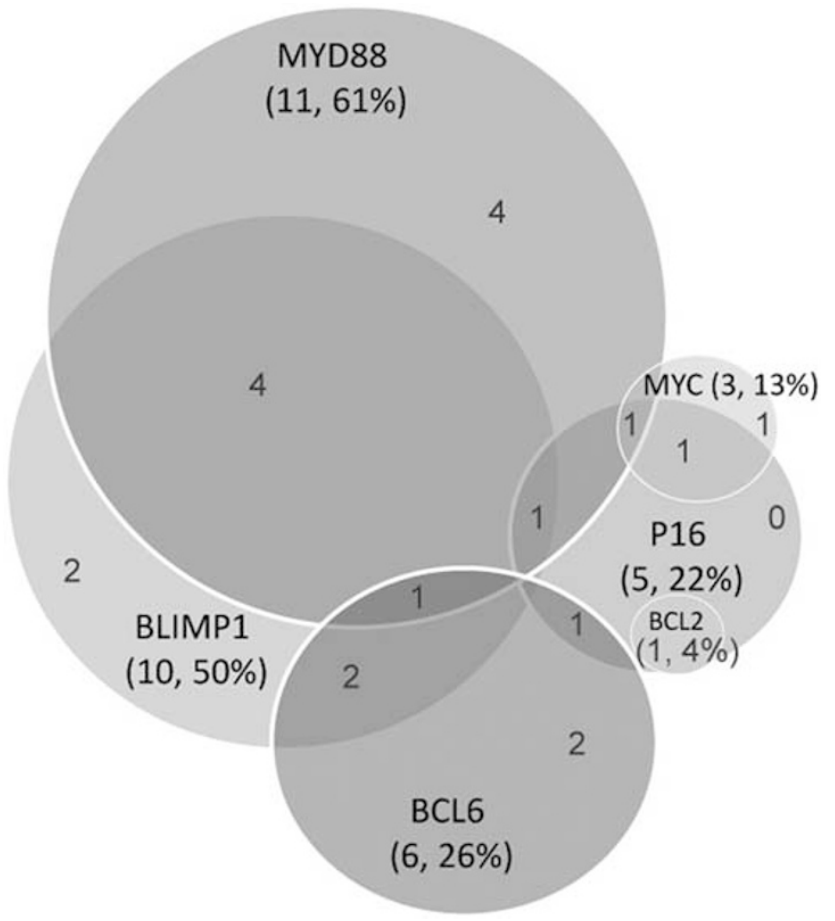

Figure 2 Overlap of MYD88 mutation with other chromosomal alterations.

Although not significant in this small series $(P=0.15)$, the presence of MYD88 mutation tend toward a shorter survival (Figure 3 ).

\section{Discussion}

In this study, we investigated a series of 23 cutaneous large B-cell lymphoma, leg type for the occurrence of gene mutations and chromosomal rearrangements or deletions in gene loci recurrently involved in nodal diffuse large B-cell lymphoma. First, we observed a very frequent rate of genetic abnormalities in 22 out of 23 cases (96\%). Second, these aberrations were the same as those reported in nodal-activated B-cell-like diffuse large B-cell lymphoma: MYD88 mutation (11/18; 61\%); BLIMP1 deletion (11/18; 61\% cases); BCL6 breakpoint (6/23; $26 \%)$; CDKN2A deletion (5/23; 22\%); $M Y C$ breakpoint $(3 / 23 ; 13 \%)$, and extra copies of several loci suggesting polyploidy. Moreover, our original FISH strategy with successive hybridization and tumor area tracking permitted us to establish that the same nuclei displayed several cytogenetic alterations.

Altogether, the cytogenetic alterations observed in our series bring primary cutaneous large B-cell lymphoma, leg type close to its activated B-cell nodal counterpart as no double-hit lymphoma was observed. For example, BCL6 rearrangements were found in $\sim 30 \%$ of nodal-activated B-cell diffuse large B-cell lymphoma. ${ }^{26,27}$ The BCL6 protein acts as transcriptional repressor, which appears to inhibit differentiation of germinal-center $\mathrm{B}$ cells toward
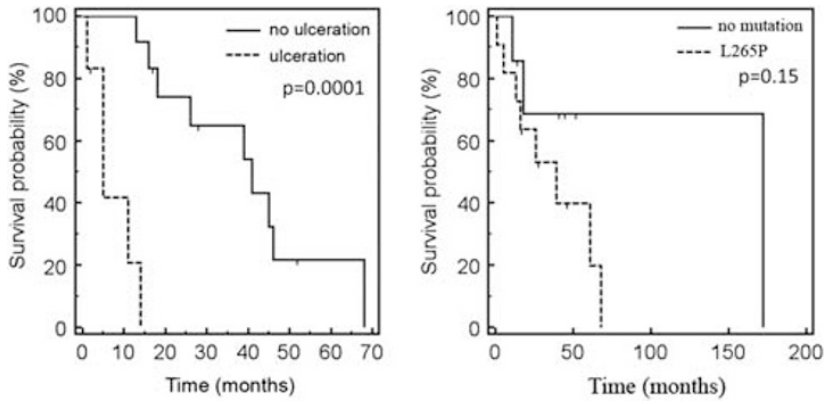

Figure 3 Overall survival according to the presence of ulceration $(P=0.0001)$ or to the presence of the MYD88 L265P-activating mutation $(P=0.15)$.

plasma cells, thereby preventing the expression of BLIMP $1 .{ }^{36}$ We also found that $\sim 50 \%$ of primary cutaneous large B-cell lymphoma, leg type carry a heterozygous deletion involving the BLIMP1 locus, either as interstitial deletion (6q21) or terminal $6 \mathrm{q}$ deletion. The latter also encompass the $6 \mathrm{q} 23$ (TNFAIP3/A20) locus, which is known to be inactivated in $\sim 30 \%$ of activated B-cell diffuse large B-cell lymphoma. ${ }^{18}$ Our data would support that BLIMP1 inactivation in primary cutaneous large B-cell lymphoma, leg type blocks B-cell terminal differentiation like in activated B-cell-like diffuse large B-cell lymphoma. ${ }^{21,37,38}$ Inactivation of BLIMP1 gene also described in $53 \%$ of activated B-cell diffuse large B-cell lymphoma would also contribute to the expression of both IRF4/MUM1 and BCL6 proteins, a frequent feature of primary cutaneous large B-cell lymphoma, leg type, ${ }^{5,14}$ which are normally exclusive during B-cell development. ${ }^{39}$

The MYC oncogene can be activated through the $\mathrm{t}(8 ; 14)(\mathrm{q} 24 ; \mathrm{q} 32)$, which is the hallmark of Burkitt's lymphoma. ${ }^{40}$ Nevertheless, $M Y C$ rearrangements have been detected in $\sim 8-14 \%$ of nodal diffuse large B-cell lymphoma and found associated with a poorer survival. ${ }^{29,30}$ Moreover, nodal 'double hit' diffuse large B-cell lymphoma combining $M Y C$ and BCL2 rearrangements have been individualized by their worse prognosis. ${ }^{41,42}$ In PCLBCL-LT, MYC rearrangement was a rare feature $(13 \%)$, while MYC expression was frequently detected whatever the $M Y C$ cytogenetic status (55\%). In fact, MYC expression in diffuse large B-cell lymphoma lacking $M Y C$ breakpoint contribute to lymphoma aggressiveness. ${ }^{35,43,44}$ Co-expression of MYC and BCL2 in diffuse large B-cell lymphoma was also shown to correlate with worse prognosis. ${ }^{43}$ Here, primary cutaneous large B-cell lymphoma, leg type frequently harbored this aggressive phenotype with strong expression of BCL2 in all cases and MYC expression in 10/18 cases.

Inactivation of the $C D K N 2 A$ region, by either deletion at chromosome 9p21.3 or promoter methylation has also been related to a poorer prognosis in primary cutaneous large B-cell lymphoma, leg type, ${ }^{8,45}$ as also reported in activated B-cell diffuse 
large B-cell lymphoma. ${ }^{31}$ Only 5/23 (21.7\%) cases of our series harbored $C D K N 2 A$ deletion. Such low rate may rely on the use of FISH with commercial probe for $C D K N 2 A$ status investigation, which may escape small deletions detected by other methods. ${ }^{8,46}$

Nodal-activated B-cell DLBCL hallmark is the constitutive activation of the NF- $\kappa \mathrm{B}$ signaling pathway that promotes cell survival, proliferation and inhibition of apoptosis. ${ }^{47}$ Mutations of B-cell receptor molecules (CD79A and CD79B) or of negative (TNFAIP3/A20) and positive (CARD11, TRAF2, TRAF5, MAP3K7/TAK1, and TNFRSF11A/RANK) regulators of $\mathrm{NF}-\kappa \mathrm{B}^{18}$ all contribute to $\mathrm{NF}-\kappa \mathrm{B}$ constitutive activation. They remain to be investigated in primary cutaneous large B-cell lymphoma, leg type by next-generation sequencing techniques. Moreover, activating mutation in the Toll/IL-1 receptor domain of MYD88 were shown to drive prosurvival NF- $\kappa \mathrm{B}$-signaling effects transactivating IRF4 and CARD11 in an oncogenic loop. ${ }^{16,19,48}$

Contrary to other primary cutaneous B-cell lymphomas subtypes that do not bear the primary cytogenetic alteration of their nodal counterpart, primary cutaneous large B-cell lymphoma, leg type seems to harbor a common genetic profile with nodal-activated B-cell diffuse large B-cell lymphoma with common primary genetic mutations of MYD88 and BLIMP1 alterations. ${ }^{16,37}$ In fact, we also included in our study four cases (cases 18-21) with a loco-regional extracutaneous involvement that were considered as primary skin disease because of a presentation on the limbs (three cases) and histological features of leg-type B-cell lymphoma. Such borderline cases also underline a continuous spectrum between cutaneous and systemic-activated B-cell lymphoma. Our data also support the presence of several genetic alterations in a single tumor, as reported in nodal-activated B-cell diffuse large B-cell lymphoma. ${ }^{16,18}$ Lenalidomide, a drug showing clinical activity in myeloma and activated B-cell diffuse large B-cell lymphoma, ${ }^{49}$ together with inhibitors of the B-cell receptor signaling pathway has been recently shown to induce synthetic lethality of activated B-cell diffuse large B-cell lymphoma cells by downregulating IRF4 and SPIB transcription factors that in turn downregulate NF- $\kappa$ B pathway. ${ }^{19}$ Such molecules could represent an attractive therapeutic option in primary cutaneous large B-cell lymphoma, leg type, as NF- $\kappa \mathrm{B}$ pathway seems to be activated ${ }^{50}$ and as most of our patients poorly responded to conventional therapy. Deciphering the multiple genetic alterations of each tumor may contribute to select patients for the appropriate inhibiting therapy.

\section{Acknowledgements}

We acknowledge the following French physicians and pathologists for providing data or samples: Sophie Dalac, CHU Dijon; Pascal Joly, CHU Rouen;
Olivier Fitoussi, Clinique Bordeaux Nord, Bordeaux; Houchinghe Eghbali, Institut Bergonié, Bordeaux; Patrick Guillot, Clinique Arès; Christine Merlio, Talence. Most samples were collected through the Tumor Bank of University Hospital of Bordeaux sponsored by a National Cancer Institute SIRIC-BRIO and Cancéropôle Grand Sud-Ouest Program. Clinical data were obtained from the Aquitaine Cutaneous Lymphoma database and the French National Study Group of Lymphoma database. This work is part of the REV-LEG Programme Hospitalier de la Recherche Clinique grant to CHU Bordeaux number 2011/28 also funded by Celgene.

\section{Disclosure/conflict of interest}

The authors declare no conflict of interest.

\section{References}

1 Vermeer MH, Geelen FA, van Haselen CW, et al. Primary cutaneous large B-cell lymphomas of the legs. A distinct type of cutaneous B-cell lymphoma with an intermediate prognosis. Dutch Cutaneous Lymphoma Working Group. Arch Dermatol 1996;132:1304-1308.

2 Willemze R, Jaffe ES, Burg G, et al. WHO-EORTC classification for cutaneous lymphomas. Blood 2005; 105:3768-3785.

3 Grange F, Beylot-Barry M, Courville P, et al. Primary cutaneous diffuse large B-cell lymphoma, leg type: clinicopathologic features and prognostic analysis in 60 cases. Arch Dermatol 2007;143:1144-1150.

4 Swerdlow SH, Campo E, Lee Harris N, et al. (eds) WHO classification of tumours of haematopoietic and lymphoid tissues. IARC: Lyon; 2008; p 242.

5 Hoefnagel JJ, Mulder MMS, Dreef E, et al. Expression of B-cell transcription factors in primary cutaneous B-cell lymphoma. Mod Pathol 2006;19:1270-1276.

6 Senff NJ, Hoefnagel JJ, Jansen PM, et al. Reclassification of 300 primary cutaneous B-Cell lymphomas according to the new WHO-EORTC classification for cutaneous lymphomas: comparison with previous classifications and identification of prognostic markers. J Clin Oncol 2007;25:1581-1587.

7 Zinzani PL, Quaglino P, Pimpinelli N, et al. Prognostic factors in primary cutaneous B-cell lymphoma: the Italian Study Group for Cutaneous Lymphomas. J Clin Oncol 2006;24:1376-1382.

8 Senff NJ, Zoutman WH, Vermeer $\mathrm{MH}$, et al. Finemapping chromosomal loss at 9p21: correlation with prognosis in primary cutaneous diffuse large B-cell lymphoma, leg type. J Invest Dermatol 2009;129: 1149-1155.

9 Alizadeh AA, Eisen MB, Davis RE, et al. Distinct types of diffuse large B-cell lymphoma identified by gene expression profiling. Nature 2000;403:503-511.

10 Rosenwald A, Wright G, Chan WC, et al. The use of molecular profiling to predict survival after chemotherapy for diffuse large-B-cell lymphoma. N Engl J Med 2002;346:1937-1947.

11 Hoefnagel JJ, Dijkman R, Basso K,J, et al. Distinct types of primary cutaneous large B-cell lymphoma identified by gene expression profiling. Blood 2005;105: 3671-3678. 
12 Hans CP, Weisenburger DD, Greiner TC, et al. Confirmation of the molecular classification of diffuse large B-cell lymphoma by immunohistochemistry using a tissue microarray. Blood 2004;103: 275-282.

13 Meyer PN, Fu K, Greiner TC, et al. Immunohistochemical methods for predicting cell of origin and survival in patients with diffuse large B-cell lymphoma treated with rituximab. J Clin Oncol 2011;29:200-207.

14 Pham-Ledard A, Prochazkova-Carlotti M, Vergier B, et al. IRF4 expression without IRF4 rearrangement is a general feature of primary cutaneous diffuse large B-cell lymphoma, leg type. J Invest Dermatol 2010; 130:1470-1472.

15 Davis RE, Ngo VN, Lenz G, et al. Chronic active B-cellreceptor signalling in diffuse large B-cell lymphoma. Nature 2010;463:88-92.

16 Ngo VN, Young RM, Schmitz R, et al. Oncogenically active MYD88 mutations in human lymphoma. Nature 2011;470:115-119.

17 Shaffer AL, Emre NCT, Romesser PB, et al. IRF4: Immunity. Malignancy! Therapy? Clin Cancer Res 2009;15:2954-2961.

18 Compagno M, Lim WK, Grunn A, et al. Mutations of multiple genes cause deregulation of NF-kappaB in diffuse large B-cell lymphoma. Nature 2009;459: 717-721.

19 Yang Y, Shaffer AL, Emre NCT, et al. Exploiting synthetic lethality for the therapy of ABC diffuse large B cell lymphoma. Cancer Cell 2012;21:723-737.

20 Lenz G, Staudt LM. Aggressive lymphomas. N Engl J Med 2010;362:1417-1429.

21 Mandelbaum J, Bhagat G, Tang H, et al. BLIMP1 is a tumor suppressor gene frequently disrupted in activated B cell-like diffuse large B cell lymphoma. Cancer Cell 2010;18:568-579.

22 Pham-Ledard A, Cappellen D, Martinez F, et al. MYD88 somatic mutation is a genetic feature of primary cutaneous diffuse large B-cell lymphoma, leg type. J Invest Dermatol 2012;132:2118-2120.

23 Grange F, Maubec E, Bagot M, et al. Treatment of cutaneous B-cell lymphoma, leg type, with age-adapted combinations of chemotherapies and rituximab. Arch Dermatol 2009;145:329-330.

24 Coiffier B, Lepage E, Briere J, et al. CHOP chemotherapy plus rituximab compared with $\mathrm{CHOP}$ alone in elderly patients with diffuse large-B-cell lymphoma. N Engl J Med 2002;346:235-242.

25 Visco C, Tzankov A, Xu-Monette ZY, et al. Patients with diffuse large B-cell lymphoma of germinal center origin with BCL2 translocations have poor outcome, irrespective of MYC status: a report from an International DLBCL rituximab-CHOP Consortium Program Study. Haematologica 2013;98:255-263.

26 Barrans SL, O’Connor SJM, Evans PAS, et al. Rearrangement of the BCL6 locus at 3q27 is an independent poor prognostic factor in nodal diffuse large B-cell lymphoma. Br J Haematol 2002;117:322-332.

27 Copie-Bergman C, Gaulard P, Leroy K, et al. Immunofluorescence in situ hybridization index predicts survival in patients with diffuse large B-cell lymphoma treated with R-CHOP: a GELA study. J Clin Oncol 2009;27:5573-5579.

28 Shustik J, Han G, Farinha P, et al. Correlations between BCL6 rearrangement and outcome in patients with diffuse large B-cell lymphoma treated with CHOP or R-CHOP. Haematologica 2010;95:96-101.
29 Barrans S, Crouch S, Smith A, et al. Rearrangement of MYC is associated with poor prognosis in patients with diffuse large B-cell lymphoma treated in the era of rituximab. J Clin Oncol 2010;28:3360-3365.

30 Savage KJ, Johnson NA, Ben-Neriah S, et al. MYC gene rearrangements are associated with a poor prognosis in diffuse large B-cell lymphoma patients treated with R-CHOP chemotherapy. Blood 2009;114: 3533-3537.

31 Jardin F, Jais J-P, Molina T-J, et al. Diffuse large B-cell lymphomas with CDKN2A deletion have a distinct gene expression signature and a poor prognosis under R-CHOP treatment: a GELA study. Blood 2010;116: 1092-1104.

32 Belaud-Rotureau M-A, Marietta V, Vergier B, et al. Inactivation of p16INK4a/CDKN2A gene may be a diagnostic feature of large $B$ cell lymphoma leg type among cutaneous B cell lymphomas. Virchows Arch 2008;452:607-620.

33 Hallermann C, Kaune KM, Siebert R, et al. Chromosomal aberration patterns differ in subtypes of primary cutaneous B cell lymphomas. J Invest Dermatol 2004;122:1495-1502.

34 Hoefnagel JJ, Vermeer MH, Jansen PM, et al. Bcl-6 and CD10 expression in cutaneous B-cell lymphoma: further support for a follicle centre cell origin and differential diagnostic significance. $\mathrm{Br} \mathrm{J}$ Dermatol 2003;149:1183-1191.

35 Kluk MJ, Chapuy B, Sinha $\mathrm{P}$, et al. Immunohistochemical detection of MYC-driven diffuse large B-cell lymphomas. PLoS ONE 2012;7:e33813.

36 Falini B, Mason DY. Proteins encoded by genes involved in chromosomal alterations in lymphoma and leukemia: clinical value of their detection by immunocytochemistry. Blood 2002;99:409-426.

37 Pasqualucci L, Compagno $\mathrm{M}$, Houldsworth J, et al. Inactivation of the PRDM1/BLIMP1 gene in diffuse large B cell lymphoma. J Exp Med 2006;203:311-317.

38 Tam W, Gomez M, Chadburn A, et al. Mutational analysis of PRDM1 indicates a tumor-suppressor role in diffuse large B-cell lymphomas. Blood 2006;107: 4090-4100.

39 Shaffer AL, Lin KI, Kuo TC, et al. Blimp-1 orchestrates plasma cell differentiation by extinguishing the mature B cell gene expression program. Immunity 2002;17: 51-62.

40 Dave SS, Fu K, Wright GW, et al. Molecular diagnosis of Burkitt's lymphoma. N Engl J Med 2006;354: 2431-2442.

41 Johnson NA, Savage KJ, Ludkovski O, et al. Lymphomas with concurrent BCL2 and MYC translocations: the critical factors associated with survival. Blood 2009;114:2273-2279.

42 Snuderl M, Kolman OK, Chen Y-B, et al. B-cell lymphomas with concurrent IGH-BCL2 and MYC rearrangements are aggressive neoplasms with clinical and pathologic features distinct from Burkitt lymphoma and diffuse large B-cell lymphoma. Am J Surg Pathol 2010;34:327-340.

43 Green TM, Young KH, Visco C, et al. Immunohistochemical double-hit score is a strong predictor of outcome in patients with diffuse large B-cell lymphoma treated with rituximab plus cyclophosphamide, doxorubicin, vincristine, and prednisone. J Clin Oncol 2012;30:3460-3467.

44 Horn H, Ziepert M, Becher C, et al. MYC status in concert with BCL2 and BCL6 expression predicts 
outcome in diffuse large B-cell lymphoma. Blood 2013;121:2253-2263.

45 Dijkman R, Tensen CP, Jordanova ES, et al. Array-based comparative genomic hybridization analysis reveals recurrent chromosomal alterations and prognostic parameters in primary cutaneous large B-cell lymphoma. J Clin Oncol 2006;24:296-305.

46 Wiesner T, Obenauf AC, Geigl JB, et al. 9p21 deletion in primary cutaneous large B-cell lymphoma, leg type, may escape detection by standard FISH assays. J Invest Dermatol 2009;129:238-240.

47 Davis RE, Brown KD, Siebenlist U, et al. Constitutive nuclear factor kappaB activity is required for survival of activated B cell-like diffuse large B cell lymphoma cells. J Exp Med 2001;194:1861-1874.

48 Rui L, Schmitz R, Ceribelli M, et al. Malignant pirates of the immune system. Nat Immunol 2011;12:933-940.

49 Hernandez-Ilizaliturri FJ, Deeb G, et al. Higher response to lenalidomide in relapsed/refractory diffuse large B-cell lymphoma in nongerminal center B-celllike thanin germinal center B-cell-like phenotype. Cancer 2011;117:5058-5066.

50 Bhagavathi S, Blenc AM, Amin M, et al. Primary cutaneous large B-cell lymphoma shows activation of nuclear factor kappa B and low incidence of EpsteinBarr virus. Am J Dermatopathol 2010;32:439-441. 